\title{
Comparative performance of squeeze film air journal bearings made of aluminium and copper
}

\author{
Chao Wang • Y. H. Joe Au
}

Received: 31 October 2011 / Accepted: 9 April 2012 /Published online: 3 May 2012

(C) The Author(s) 2012. This article is published with open access at Springerlink.com

\begin{abstract}
Two tubular squeeze film journal bearings, made from $\mathrm{Al} 2024 \mathrm{~T} 3$ and $\mathrm{Cu} \mathrm{C} 101$, were excited by driving the single-layer piezoelectric actuators at a $75-\mathrm{V}$ AC with a $75-\mathrm{V}$ DC offset. The input excitation frequencies were coincident with the 13th modal frequency, at 16.32 and $12.18 \mathrm{kHz}$ for the respective $\mathrm{Al}$ and $\mathrm{Cu}$ bearings, in order to produce a 'triangular' modal shape. The paper also provided a CFX model, used to solve the Reynolds equation and the equation of motion, to explain the squeeze film effect of an oscillating plate with pressure end leakage. The dynamic characteristics of both bearings were studied in ANSYS and then validated by experiments with respect to their squeeze film thickness and loadcarrying capacity. It was observed that whilst both bearings did levitate a load when excited at mode 13 , the $\mathrm{Al}$ bearing showed a better floating performance than $\mathrm{Cu}$ bearing. This is due to the fact that the Al bearing had a higher modal frequency and a greater amplitude response than the $\mathrm{Cu}$ bearing.
\end{abstract}

Keywords Single-layer piezoelectric actuator · Squeeze film bearing $\cdot$ Reynolds equation $\cdot$ Pressure leakage $\cdot$ Mode shape $\cdot \mathrm{Al}$ bearing and $\mathrm{Cu}$ bearing

\section{Introduction}

In modern-day engineering, it is necessary to have bearings that can operate with high-precision motion, low friction and wear, generating very little heat in an oil-free condition [1]. In this respect, aerostatic and aerodynamic bearings have been

C. Wang · Y. H. J. Au $(\bowtie)$

Advanced Manufacturing and Enterprise Engineering,

School of Engineering and Design, Brunel University,

Uxbridge, UK

e-mail: joe.au@brunel.ac.uk developed and can meet the requirements, except for the fact that ancillary equipment is needed for their satisfactory operation. The equipment typically consists of air compressors and hoses, all of which take up space and are not very portable, which is a significant obstacle to the miniaturization of machine tools for micro- or nanomachining.

To study the bearing behaviour of a thin air film between two surfaces, the Reynolds equation is used. Stolarski and Chai [1] identified three mechanisms from the equation that would show a pressure-generating phenomenon, which gives the bearing its load-carrying capability. The first refers to the 'physical wedge' as is found in hydrodynamic bearings where the fluid flows through a wedge; the second requires the two surfaces to contract or expand in plane in order to create a variable velocity on the bearing surfaces; the third requires that the two bearing surfaces move normal to each other with an oscillating velocity and is known as the 'squeeze film' effect. Stolarski and Chai [1] asserted that the pressure generated by the hydrodynamic and squeeze film effects is of a similar order of magnitude, hence the justification for exploring the latter in the design of a new type of bearing. Squeeze film bearings have the significant advantage due to the fact that they do not require air compressors and connecting hoses; the equipment needed for generating the squeeze film action is far smaller, and it can be miniaturised to the extent that it becomes a single package with the bearing.

Both Stolarski and Woolliscroft [2] and Yoshimoto et al. [3] designed their squeeze film air bearings in Al with elastic hinges. The bearings were excited with stack piezoelectric actuators at a frequency of just around several kilohertz, which was somewhat lower than the fundamental frequency of the bearing structure. This does not take advantage of the mechanical gain achieved when the structure is driven near or at one of its modal frequencies. Using elastic hinges can weaken a structure, increasing the 
dynamic response and the manufacturing cost. The low operation frequency, being in the audible range, can make the bearings noisy. In 2006, Yoshimoto et al. [4, 5] presented the research into a new type of bearing that was excited at an ultrasonic frequency with single-layer piezoelectric actuators, thus removing potential audible noise during operation. Moreover, driving single-layer piezoelectric actuators requires less power than multilayer counterparts.

This paper attempts to compare the static and dynamic characteristics of squeeze film bearings made from two different materials, namely aluminium and copper, given the same geometry. Different materials have different mechanical properties such as the Young's modulus and the density. The Young's modulus affects the stiffness of the bearing, whereas the density affects its mass; both control the natural frequency. The stiffness also influences the vibration amplitude of the bearing and, consequently, the squeeze film thickness and the load-carrying capacity.

In order to investigate the aforementioned observations, the objectives of the work reported in this paper were:

1. To develop a CFX model to explain the squeeze film effect taking account of the pressure end leakage;

2. To perform a modal analysis in ANSYS for the two bearings;

3. To develop an ANSYS model to compare the static and dynamic deformation of the two bearings;

4. To investigate and compare the levitation characteristics, in terms of the air film thickness and load-carrying capacity, between the two bearings using a CFX simulation model.

\section{Theory of squeeze air film for flat plates}

\subsection{Reynolds equation}

Consider an air film that is squeezed between two flat plates having a relative sinusoidal motion of frequency $\omega$ at amplitude $e$, in the direction of the film thickness, as shown in Fig. 1a. The pressure at a point in the air film is governed by the Reynolds equation

$\frac{\partial}{\partial X}\left(H^{3} p \frac{\partial p}{\partial X}\right)+\frac{\partial}{\partial Z}\left(H^{3} p \frac{\partial p}{\partial Z}\right)=2 \sigma \frac{(\partial P H)}{\partial \tau}$
Equation 1 is given in non-dimensional form [6]. $X, Y$ and $Z$ are the coordinates of a point in the air film expressed as a fraction of its length, width and thickness, respectively; $P=\frac{p}{p_{0}}$ is the ratio of the instantaneous pressure to the initial pressure; $H$ the ratio of the instantaneous to the initial film thickness; $\sigma$ the squeeze number; and $\tau=\omega t$ the non-dimensional time obtained as the product of the angular frequency of oscillation $\omega$ and time $t$.

The squeeze number is defined as $\sigma=\frac{12 \mu \omega L^{2}}{p_{0} h_{0}^{2}}$, where $\mu$ is the dynamic viscosity and $L$ the length of the air film.

The instantaneous film thickness $h=h_{0}+e \sin (\tau)$, and hence the instantaneous film thickness ratio, being $h / h_{0}$, is given by $H=1+\varepsilon \sin (\tau)$.

\subsection{Equation of motion of flat plates}

If now the bottom plate is given a sinusoidal motion normal to its surface whilst the top plate is supported by the air film, the top plate will be caused to move in a manner governed by Newton's second law, namely

$\mathrm{mTop} \cdot \frac{d}{\mathrm{~d} t}(\operatorname{velTop})=F_{\mathrm{L}}-\mathrm{mTop} \cdot g$

In Eq. 2, mTop and velTop are the respective mass and velocity of the top plate, $F_{\mathrm{L}}$ is the levitation force exerted by the air film, and (mTop.g) is the weight force of the top plate.The time derivative of the velocity of the top plate can be discretized as

$$
\frac{d}{d t}(\text { velTop })=\frac{\text { velTopNew }- \text { velTopOld }}{t \text { Step }}
$$

where

velTopNew $=\frac{\text { dTopNew }- \text { dTopOld }}{t \text { Step }}$

Finally, the new displacement of the top plate can be obtained by substituting Eqs. 3 and 4 into Eq. 2 to give

$$
\begin{aligned}
\text { dTopNew }= & \frac{F_{L} \times t \text { Step }^{2}}{\text { mTop }} \\
& +\left(\text { dTopOld }+ \text { velTopOld } \times t \text { Step }-g \times t \text { Step }^{2}\right)
\end{aligned}
$$

Equation 1 computes the pressure profile of the air film between the two plates. From the pressure profile, the force
Fig. 1 a Dimensions of the plates and the air film thickness. b Air film in the rectangular coordinate system used a

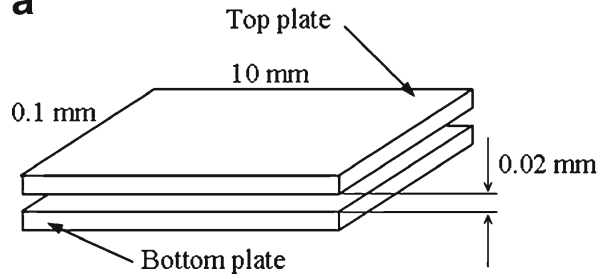

b

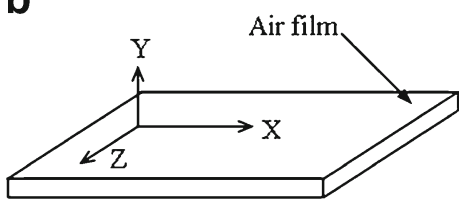


of levitation, $F_{\mathrm{L}}$, is obtained. The corresponding value of velocity, $v$, can then be found from Eq. 2, from which the displacement of the top plate is calculated by integration. This displacement, together with the sinusoidal motion of the bottom plate, changes the air film thickness, $h$, and hence the thickness ratio, $H$. This, in turn, changes the pressure profile as computed from Eq. 1. By repeating the aforementioned calculation procedure over time, it is possible to determine the corresponding displacement response of the top plate [7].

\subsection{CFX model of oscillating plates}

A model considered is the one shown in Fig. 1a, with dimensions of the plates and the initial air film thickness as indicated. The bottom plate was given a sinusoidal motion, whilst the top plate, of mass $6.24 \times 10^{-3} \mathrm{~kg}$, responded also with a sinusoidal motion. The air film, as shown in Fig. 1b, is assumed to have no leakage around the three sides of its edges, namely the left, front and back sides, but there is leakage from the right side. Such assumptions are justified by the following considerations:

1. The left side is on the plane of symmetry of the complete air film. In other words, what is shown in Fig. 1b is only the right half, and hence there is no sideway flow of air across the symmetry plane.

2. The front and back sides are also symmetrical, which means the plate is infinite along the $Z$ direction.

3. The right side, however, is exposed to the atmosphere, and pressure end leakage is expected.

The computation was performed with CFX [8] instead of home-built programming codes [2] to save time. To ensure higher accuracy in computation, the air film was meshed with hexahedron elements whose length-to-width ratio is normally less than 20:1. Accordingly, the air film was divided into 100 segments in the $X$ direction and four segments in the $Y$ and $Z$ directions. The simulation for the transient analysis was conducted over a time period of $0.2 \mathrm{~s}$, with a time step of $6 \times 10^{-6} \mathrm{~s}$, and an initial film thickness of $20 \mu \mathrm{m}$. This time period was long enough to allow the system to reach its steady state and, hence, the final film thickness.

\subsection{CFX modelling results}

Figure 2 shows the relationship between the minimum air film thickness and the oscillation frequency of the bottom plate (oscillation amplitude of $1 \mu \mathrm{m}$ ). It is observed that the air film thickness at first increases with oscillation frequency, but it reaches a constant value beyond around $15 \mathrm{kHz}$ [9].

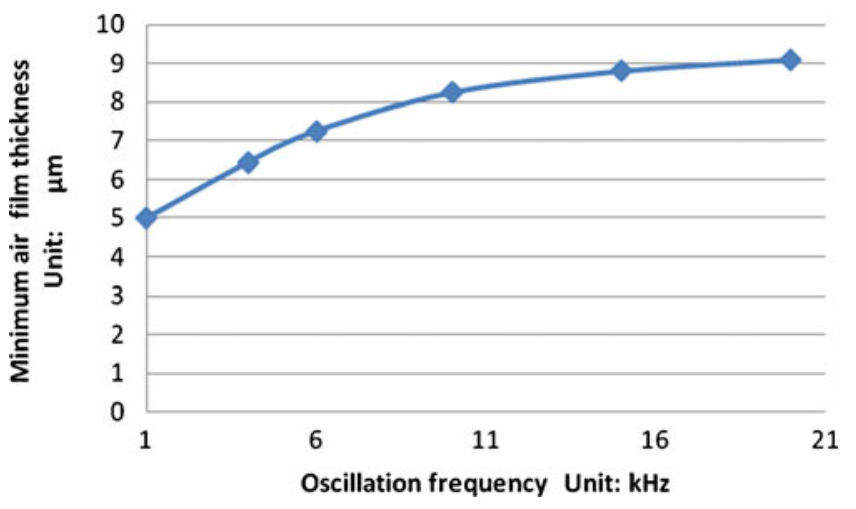

Fig. 2 Minimum air film thicknesses versus the excitation frequency of the bottom plate (oscillation amplitude, $1 \mu \mathrm{m}$ )

Figure 3 shows the relationship between the minimum air film thickness and the oscillation amplitude with the oscillation frequency of the bottom plate kept at $10 \mathrm{kHz}$ [9]. It is noted that as the oscillation amplitude increases, the air film thickness increases in an exponential fashion. The secondorder polynomial trend line fits the CFX simulation result well, as indicated by the $R^{2}$ value of 0.9999 . The polynomial equation is also displayed in Fig. 3 and can be used to predict the air film thickness for oscillation amplitudes in the range between 1 and $5 \mu \mathrm{m}$.

Figure 4 shows the steady-state pressure distribution of the air film over a period of oscillation along the $x$-axis (Fig. 1b) from the left edge $(x=0 \mathrm{~mm})$ to the right edge $(x=10 \mathrm{~mm})$ where the air film interfaces with the atmosphere whose pressure ratio $P$ is 1 . There are nine pressure profile curves shown, and they represent the pressure at different time instants in the cycle of oscillation such that the time interval between successive points, for example P1 and $\mathrm{P} 2$, is constant, being $12.5 \mu \mathrm{s}$. It is noted that the averaged pressure ratio in the film at any distance is above unity; thus, an upthrust is created to levitate the top plate. The same conclusion was drawn by the authors in their paper using the theory of ideal gas law [10].

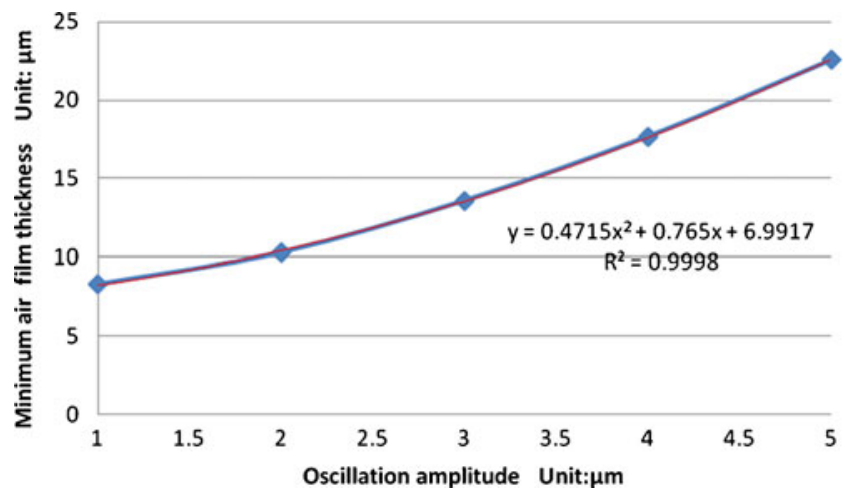

Fig. 3 Minimum air film thickness versus the oscillation amplitude of the bottom plate (oscillation frequency, $10 \mathrm{kHz}$ ) 


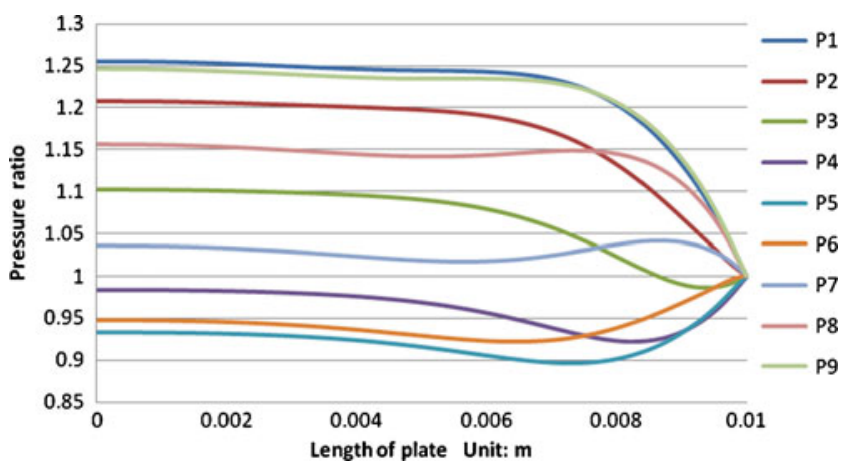

Fig. 4 Steady-state pressure distribution in the $x$ direction (Fig. 1b) of air film in a period of oscillation of the bottom plate at $10 \mathrm{kHz}$

\section{Modelling of the proposed squeeze film air bearing}

\subsection{Configuration of the bearing}

Figure 5 shows a squeeze film air bearing. It consists of a guide way and a squeeze film air bearing with three longitudinal flats $120^{\circ}$ apart. On each flat surface, two singlelayer piezoelectric actuators were bonded.

The guide way, made of structural carbon steel, is a round rod fixed at one end and free at the other, with an overhang of $130 \mathrm{~mm}$; the short overhang is desired to avoid sagging due to its own weight. The diameter of the round rod is $19.99 \mathrm{~mm}$, and the surface was ground-finished. The natural frequency of the round guide way set up as a cantilever was about $800 \mathrm{~Hz}$.

The two bearings, one made of the material A12024 T3 (Al bearing) and the other made of $\mathrm{Cu} \mathrm{C} 101$ ( $\mathrm{Cu}$ bearing), have the same dimensions, with a diameter of $20.02 \mathrm{~mm}$, a length of $60 \mathrm{~mm}$ and a thickness of $2 \mathrm{~mm}$. Three fins, each $20 \mathrm{~mm}$ long, are positioned $120^{\circ}$ apart on the outer circumference of the bearing. These fins are designed to provide a desirable modal shape when excited by actuators. The desirable modal shape is that of a 'triangle' (see Fig. 7 where the scale for radial displacement is grossly magnified) and is

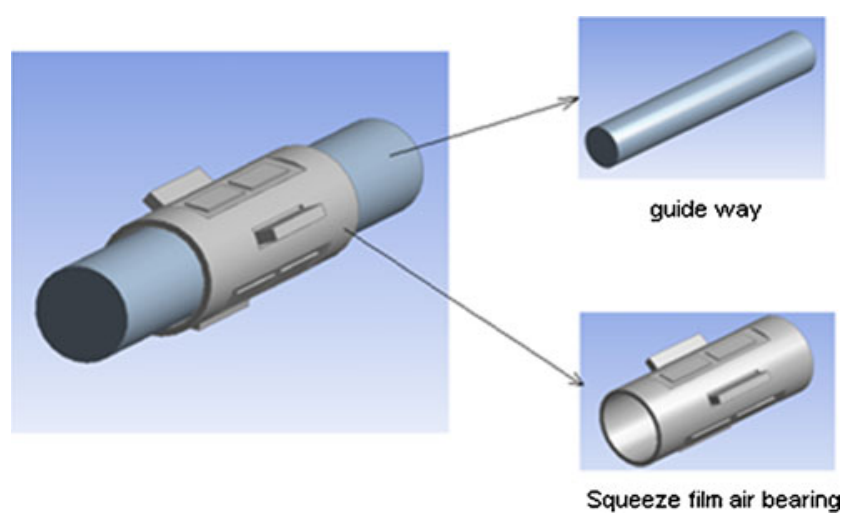

Fig. 5 Squeeze air film bearing and its components: a guide way, a bearing and six piezoelectric actuators bonded to the three flat surfaces in the cross-sectional plane of maximum vibration. This enables the air gap underneath the actuators to behave effectively as a squeeze air film.

The number of flats on the circumference of a tubular bearing has to be odd. This way, loading in any direction can be effectively countered by the presence of a squeeze air film. Three flats, and hence three fins, are preferred to five or more flats because of the larger static and dynamic deformation that can be produced under the same driving conditions.

The design does not rely on complex elastic hinges to provide local flexibility, as used by other researchers [2, 3], in order to achieve greater deflection of elements. Being a simpler design, its manufacturing cost is much lower and the bearing can be adequately driven by a single-layer piezoelectric actuator $(0.5 \mathrm{~mm}$ thick) with little power to provide the sinusoidal squeeze film motion [4]. Furthermore, the simple geometry of the design makes for subsequent simpler finite element analysis.

\subsection{Experimental setup}

Figure 6 shows a schematic diagram of the experimental setup. The items of equipment used were:

1. A signal generator: $0-5 \mathrm{~V}$ and $0-100 \mathrm{kHz}$ (SJ Electronics)

2. An actuator driver: ENP-1-1U (Echo Electronics)

3. An actuator driver monitor: ENP-50U (Echo Electronics)

4. A capacitive displacement sensor and a gauging module: MicroSense 6810; measurement bandwidth up to $100 \mathrm{kHz}$; measurement ranges from $20 \mu \mathrm{m}$ to $2 \mathrm{~mm}$; resolution, $0.25 \mathrm{~nm} \mathrm{rms}$ at $5 \mathrm{kHz}$ over a $50-\mu \mathrm{m}$ measurement range (Ixthus)

5. A data acquisition card: PXI 6110 (National Instruments)

The signal generator created a sinusoidal wave which was amplified by the actuator driver and shaped by the actuator monitor to provide an excitation signal, with a 75-V DC offset and a $75-\mathrm{V}$ peak to zero $\mathrm{AC}$ sinusoid. This excitation signal was used to drive the single-layer piezoelectric actuators. The vibration response of the structure caused by the actuators was measured by the capacitance displacement sensor whose output was sampled into a $\mathrm{PC}$ via the data acquisition card driven by a LabVIEW programme.

\subsection{Modal analysis}

Modal analysis can determine the theoretical vibration characteristics, in terms of natural frequencies and mode shapes, of a structure or a machine component. The natural frequencies and mode shapes are important parameters in the design of a structure for dynamic loading conditions, and the natural frequencies are determined by the material properties, shapes of a structure and boundary conditions. It is believed 


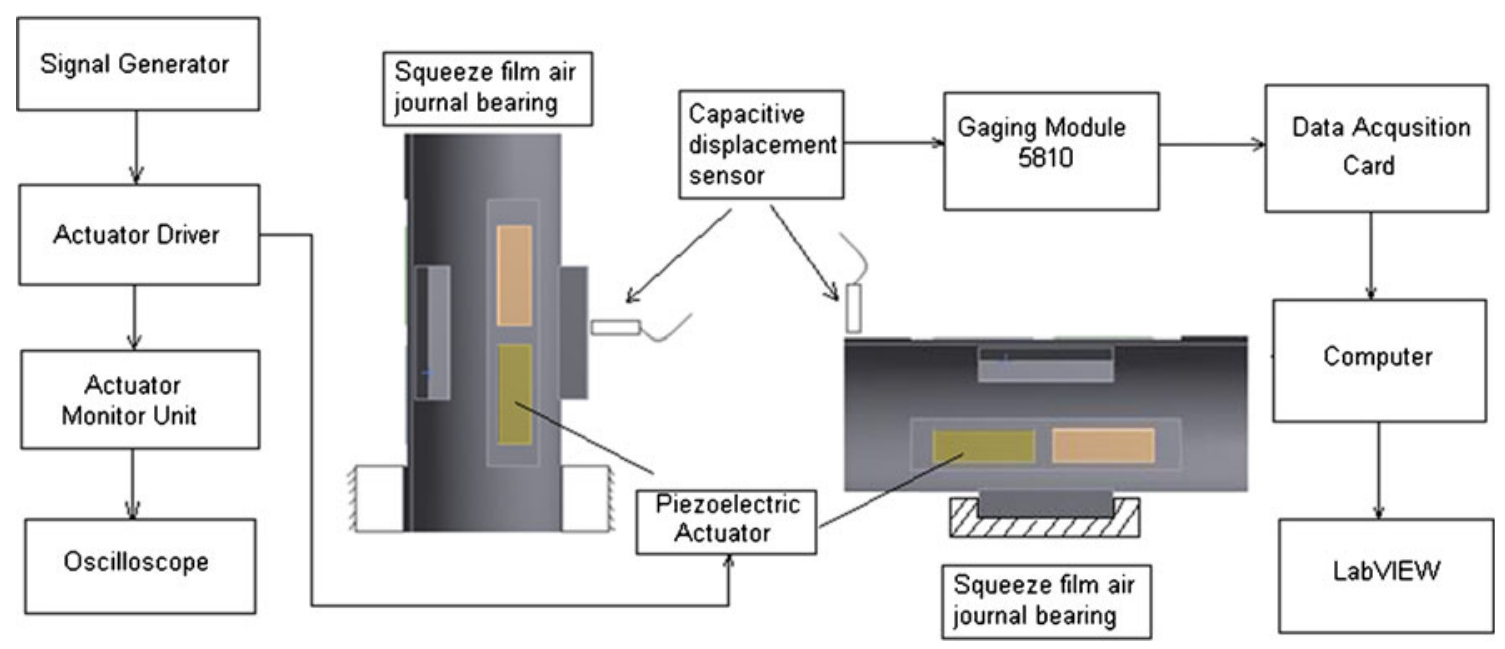

Fig. 6 Schematics of the experimental setup

that certain mode shape and material of the squeeze film air bearing can enhance the effectiveness of the squeeze air film in journal bearings.

From finite element analysis (FEA) modal modelling, mode 13 was identified to have the desirable geometry at the natural frequencies of $16.37 \mathrm{kHz}$ for the $\mathrm{Al}$ bearing and $12.32 \mathrm{kHz}$ for the $\mathrm{Cu}$ bearing. The shape of mode 13 is shown in Fig. 7, where the red end of the colour spectrum denotes greater deformation. It is observed that mode shape 13 produces flexing of the shell on the sleeve into a

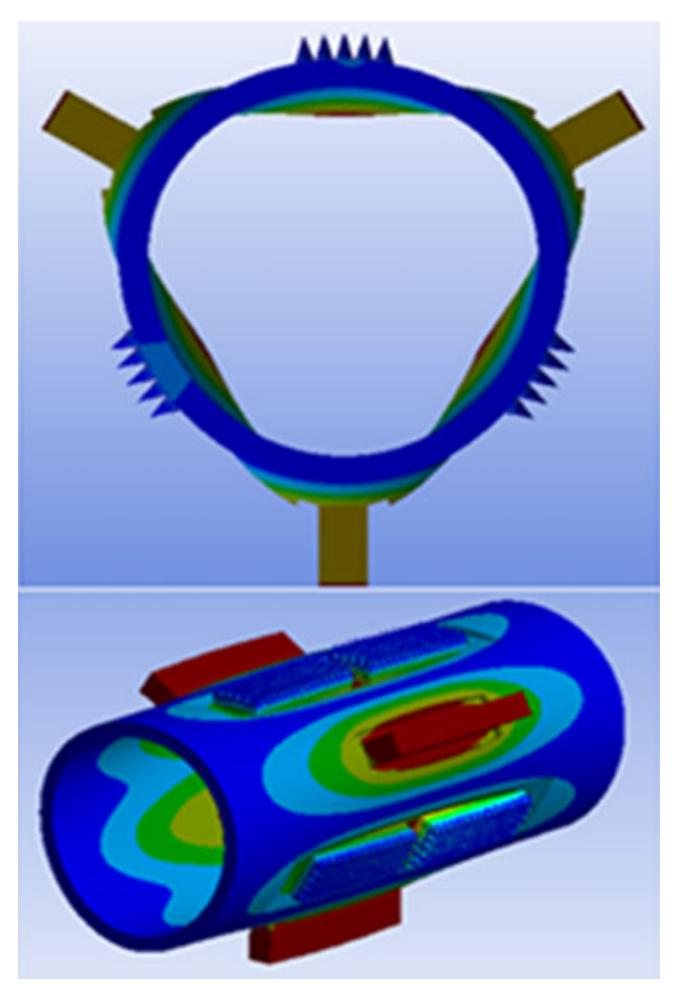

Fig. 7 Mode shape 13 of bearings: upper, end view; lower, perspective view triangular shape. At mode 13, the outer edges of the round sleeve do not appear to deform much, whilst the middle section deforms noticeably.

To create mode 13, all six piezoelectric actuators need to be driven in synchronisation at the natural frequency of the mode shape.

\subsection{Static and dynamic analysis}

\subsubsection{Static analysis}

The purpose of the static analysis was to determine the static deformation of the sleeve bearing when a $75-\mathrm{V}$ DC voltage $(0 \mathrm{~V}$ on the bottom and $75 \mathrm{~V}$ on the top surfaces of piezoelectric layer) was applied to the six single-layer piezoelectric actuators. Figure 8 shows the result of the analysis for $\mathrm{Al}$ bearing, from which a maximum radial deformation of $0.124 \mu \mathrm{m}$ is seen to occur in the middle section of the sleeve.

The aforementioned analysis was repeated for $\mathrm{Cu}$ bearing, and Fig. 9 shows the comparison of the static deflection between $\mathrm{Al}$ bearing and $\mathrm{Cu}$ bearing when the $\mathrm{DC}$ voltage was applied. In Fig. 9, it can be observed that the Al bearing has a bigger deformation than the $\mathrm{Cu}$ bearing in the same boundary conditions and that the static deformation is linearly proportional to the voltage input [2].

In the FEA modelling process, the force of the piezoelectric actuators as it varies with the driving voltage was accurately represented. This is unlike the approximations that most other researchers, for example [2], made by assuming that a maximum blocking force exists for all boundary conditions.

\subsubsection{Dynamic analysis}

Dynamic analysis is used to determine the dynamic response of a structure under the dynamic excitation force. 
Fig. 8 Static deformation of the bearing when a $75-\mathrm{V}$ DC voltage was applied to the six actuators

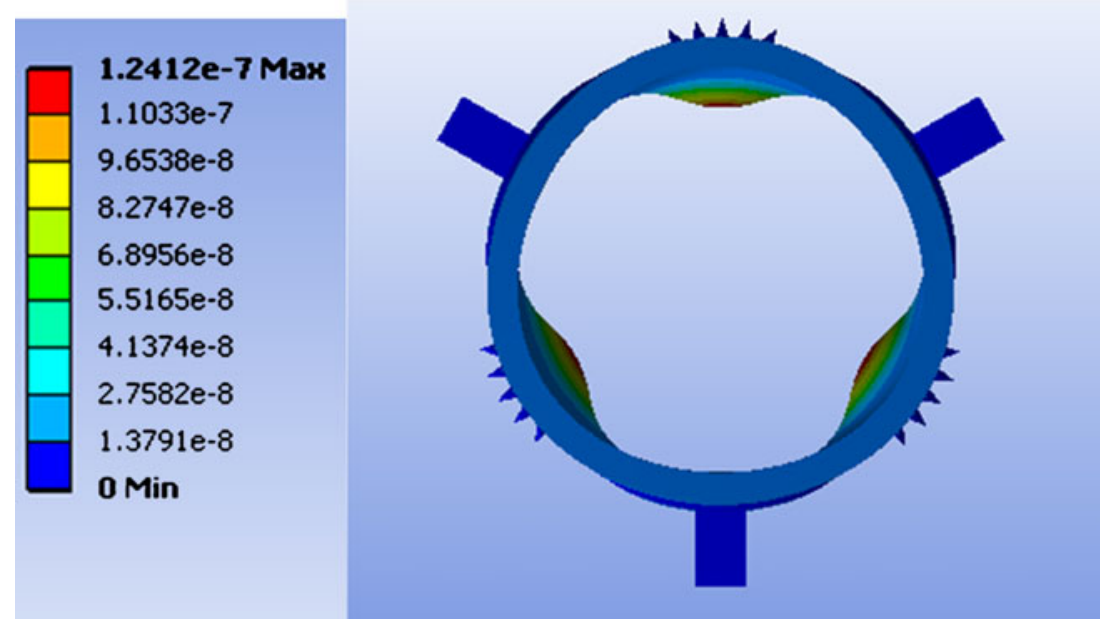

The dynamic excitation forces are from the expansion and the compression of the piezoelectric actuators when they are loaded with an AC voltage (75 V) on top of a DC offset $(75 \mathrm{~V})$. The excitation frequency should be coincident with the natural frequencies of mode 13, as identified in Section 3.3 , in order to achieve maximum dynamic response.

A dynamic experiment was performed to verify the bearing's natural frequencies and mode shapes at modes 13 . The bearing was placed on a horizontal flat surface, as shown in Fig. 10, and was supported at two positions near the bottom edge. These points of contact were chosen to coincide with the nodal points (of no displacement) of the bearing.

According to the FEA simulation for mode 13, the fins on the tubular bearing have translation motion. To verify this prediction, with the bearing excited at mode 13 , the displacement amplitude at three points - top, middle and bottom-along the length of the fin was measured with the capacitive displacement sensor. The results confirm the prediction from FEA simulation. Further measurements made on the other two fins showed the same results, but stationary (zero displacement amplitude) at both ends. For this reason, subsequent dynamic experiments only attempted to measure the displacement amplitude at one single position, as shown in Fig. 10.

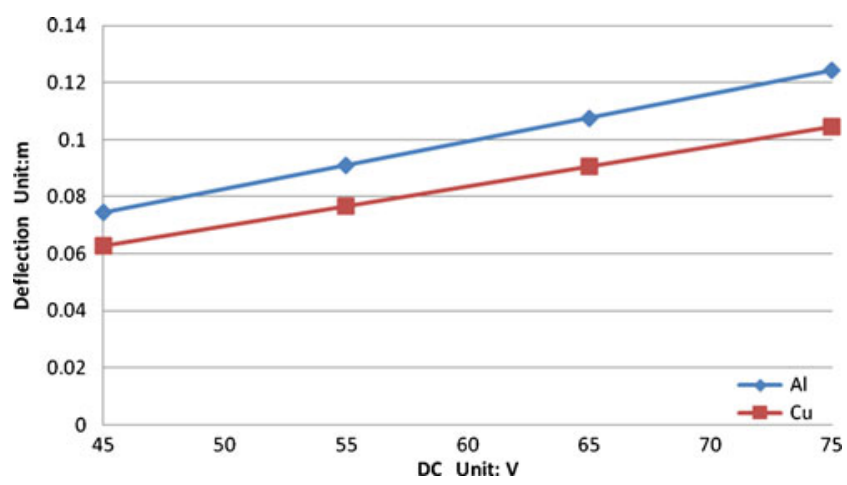

Fig. 9 Static deflection of the $\mathrm{Al}$ and $\mathrm{Cu}$ bearings based on $\mathrm{DC}$ voltages
The experimental procedure for measuring the dynamic response of $\mathrm{Al}$ bearing is as follows:

1. The bearing tube (Fig. 10) was held at the nodes (points of zero displacement) identified from the FEA modal analysis, and the displacement sensor was positioned at the point of maximum dynamic deformation also predicted from the modal analysis.

2. The coupling mode in the voltage input setup of the data acquisition card was set to ' $\mathrm{AC}$ ' so that only the dynamic, rather than static, response was measured.

3. The piezoelectric actuator on the flats of the bearing was driven at and around the natural frequency, identified from the FEA modal analysis, with a DC offset of $75 \mathrm{~V}$ and a 75-V AC at a particular driving frequency, and the dynamic deformation recorded over ten cycles of oscillation.

4. The average and the standard error (that is, standard deviation of the average) were then estimated of the displacement amplitude over the ten cycles.

5. Steps 3 and 4 were repeated for other driving frequencies.

6. Steps 1 to 5 were repeated for $\mathrm{Cu}$ bearing.

Figure 11 shows the displacement amplitude of a point on the fin of the bearing as measured by the capacitive

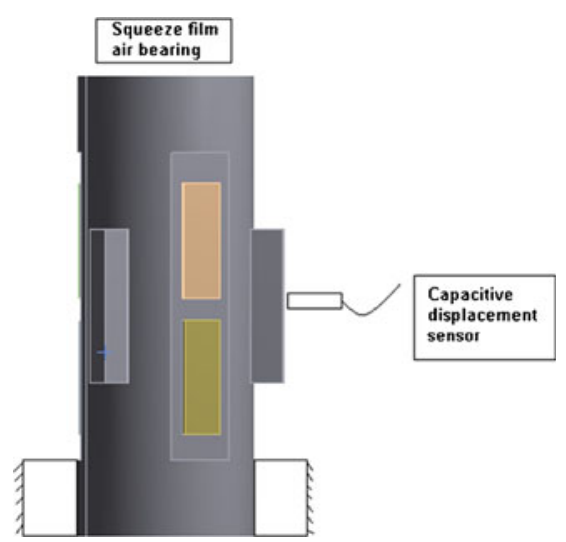

Fig. 10 Setup for the dynamic response measurement 


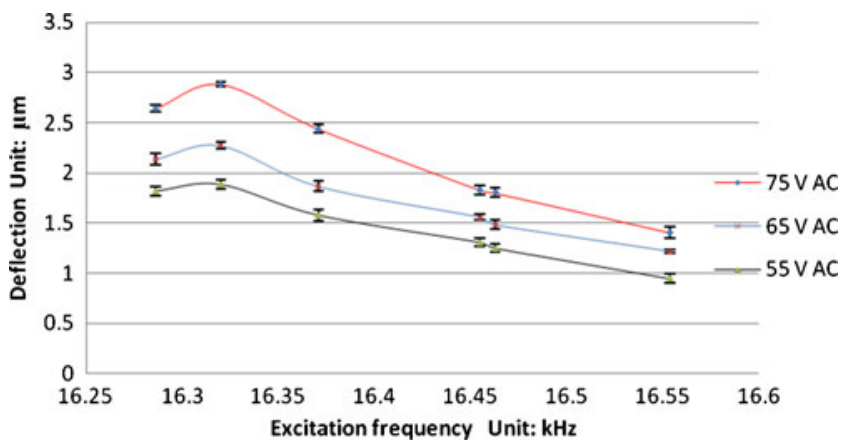

Fig. 11 Displacement amplitude on the fin of the Al bearing at mode 13 versus the excitation frequency for the three levels of $\mathrm{AC}$ input. Error bars represent \pm 2 standard errors

displacement sensor. Measurements were made ten times, and it is the average that is shown on the graph; the corresponding error bar represents \pm 2 standard errors. The narrow extent of the error bars suggests good measurement repeatability and high precision of the displacement amplitude obtained.

To correctly locate the natural frequency, the actuators were driven to excite the bearing over a range of frequencies from 16.28 to $16.55 \mathrm{kHz}$ at three different levels of $\mathrm{AC}$ voltage, namely 75,65 and $55 \mathrm{~V}$. The natural frequency for mode 13, from Fig. 11, is $16.32 \mathrm{kHz}$, at which the displacement amplitude on the fin is the greatest, for example, at $75 \mathrm{~V} \mathrm{AC}$, the displacement is $2.88 \mu \mathrm{m}$. Since the $75-\mathrm{V}$ AC gives the greatest displacement amplitude, which in turn produces the greatest mean pressure ratio, this condition was going to be used for driving the bearing subsequently.

The experiment was repeated for $\mathrm{Cu}$ bearing. The results are shown in Fig. 12. It is noted that the natural frequency and the maximum displacement response for $\mathrm{Cu}$ bearing is $12.18 \mathrm{kHz}$ and $2.41 \mu \mathrm{m}$, respectively. Figure 13 is to compare the theoretical and the experimental results of the dynamic deformation for $\mathrm{Al}$ and $\mathrm{Cu}$ bearing. The result

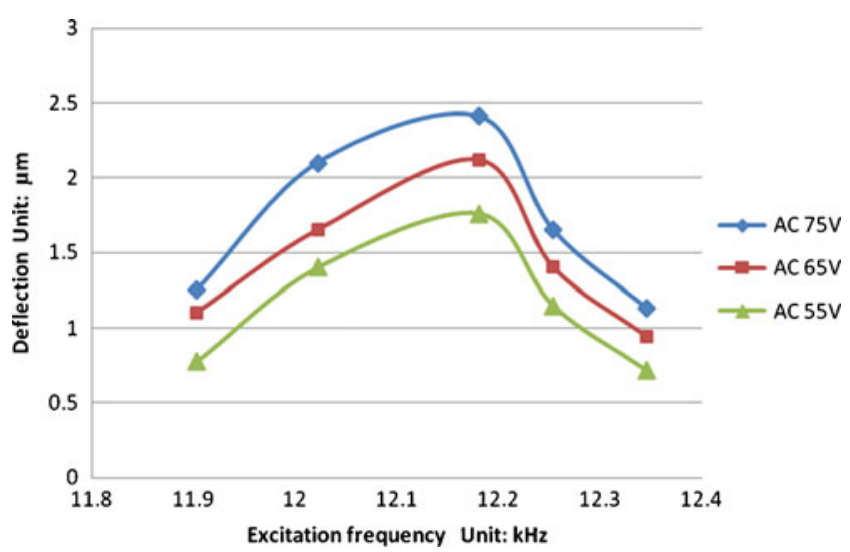

Fig. 12 Displacement amplitude on the fin of the $\mathrm{Cu}$ bearing at mode 13 versus the excitation frequency for the three levels of AC input

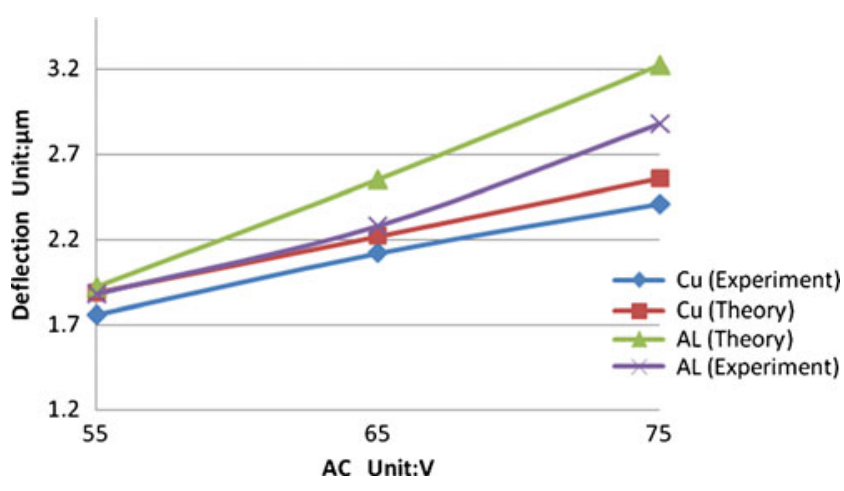

Fig. 13 Comparison between the theory and the experiment of dynamic deformation for the $\mathrm{Al}$ and $\mathrm{Cu}$ bearings $(\mathrm{DC}=75 \mathrm{~V}$, variable $\mathrm{AC})$

shows the greater dynamic displacement of the $\mathrm{Al}$ bearing than $\mathrm{Cu}$.

\section{Load-carrying capacity experiments}

In these experiments, the bearing was inserted into the round guide way, as shown in Fig. 14, set up as a cantilever. A mass was hung onto a wire attached to a fin of the bearing and the bearing was excited at a number of excitation frequencies near a particular mode. Using the measurement from the displacement sensor, it is possible to calculate the instantaneous film thickness in the vertical plane of the bearing.

To account for the fact that the $\mathrm{Al}$ bearing is lighter than the $\mathrm{Cu}$ bearing, a compensating mass was firmly affixed to the fin on the underside of the $\mathrm{Al}$ bearing to bring their masses to the same value. In this way, the additional weight

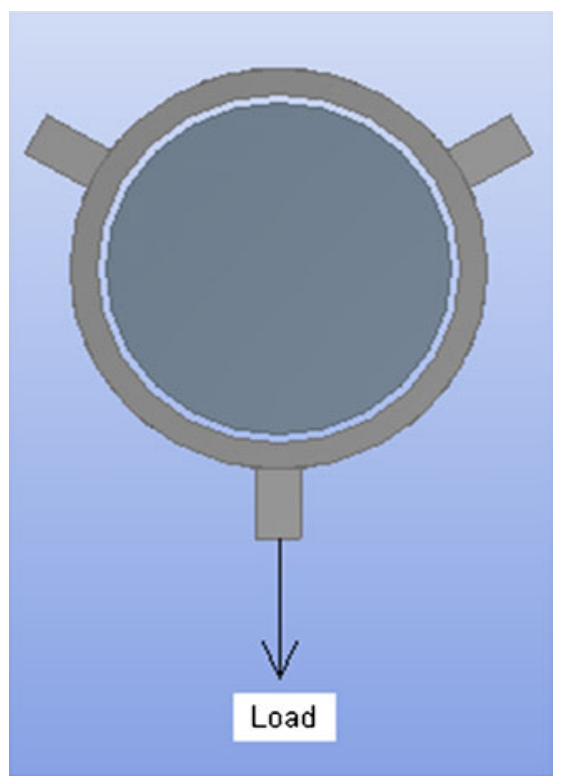

Fig. 14 Direction of loading by hanging masses 


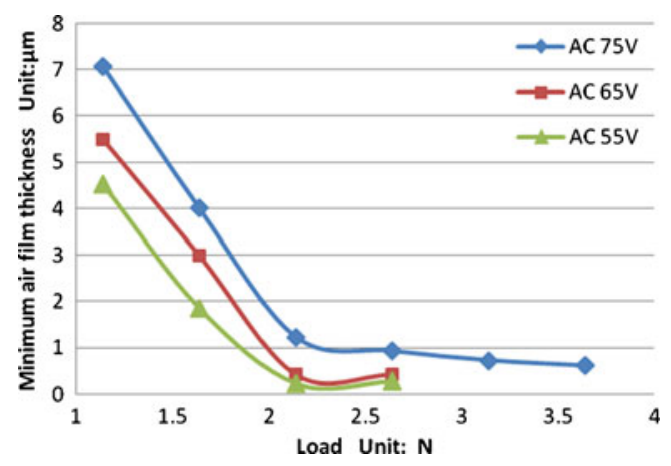

Fig. 15 Minimum air film thickness driven in the variable AC, namely 55,65 and $75 \mathrm{~V}$

hung at the end of the wire would represent the true load that both bearings had to carry.

For the minimum air film thickness measurements, the capacitive displacement sensor was positioned at the top of the tubular bearing diametrically opposite to the hanging weight, with the capacitive sensor right over the point of maximum amplitude of oscillation as predicted by the FEA modelling. Thus, for mode 13, the point was at the mid-span of the bearing's length. The sensor was zeroed when the bearing was at rest on the round guide way. As the bearing was excited by the surface-mounted piezoelectric actuators, the bearing began to float. This resulted in a non-zero displacement output comprising an alternating component superimposed on a mean component. This mean component is the mean film thickness, and the minimum film thickness is the mean minus the amplitude of oscillation. In the experiments, the minimum film thickness was computed over a thousand cycles of oscillations.

Figure 15 shows the relationship between the minimum film thickness and load when Al bearing is excited in $16.34 \mathrm{kHz}$ slightly away from the natural frequency of $16.32 \mathrm{kHz}$. The minimum film thickness driven at $75 \mathrm{~V}$ $\mathrm{AC}$ is greater than the others; the minimum film thickness is nearly zero when the load is beyond $2 \mathrm{~N}$ driven at 65 and $55 \mathrm{~V}$ AC. In order to achieve the greater film thickness, the $75-\mathrm{V} \mathrm{AC}$ is chosen for the rest of the analysis.

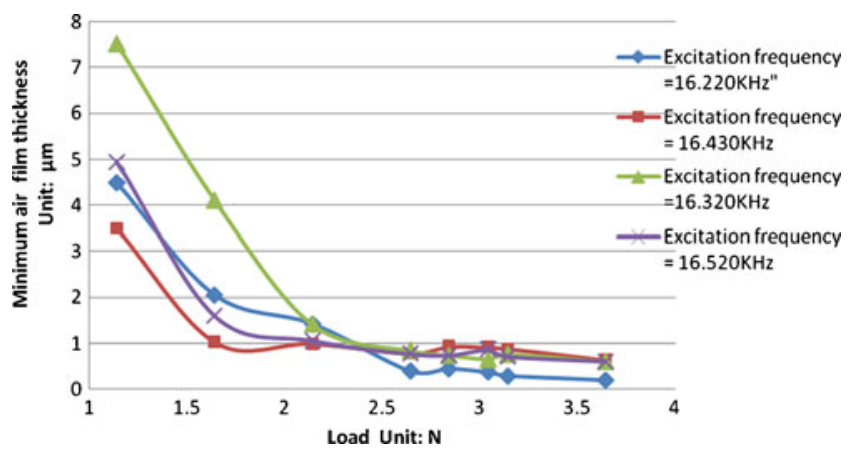

Fig. 16 Minimum air film thickness of the Al bearing versus load at four excitation frequencies

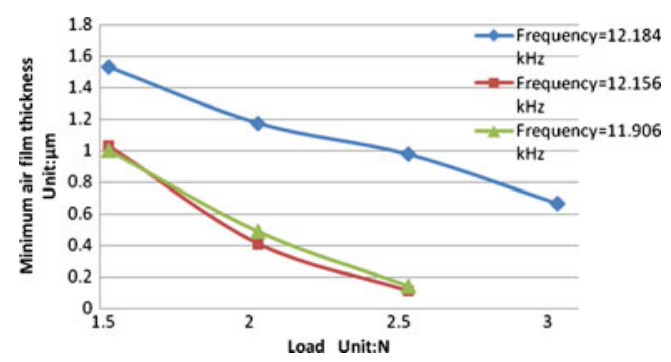

Fig. 17 Floating test based on the variable excitation frequencies for the $\mathrm{Cu}$ bearing

Figure 16 shows the relationship between the minimum film thickness and load at four different excitation frequencies at and around the natural frequency of mode 13. At the natural frequency of $16.32 \mathrm{kHz}$, the minimum air film thickness is greater than those at other frequencies below a load of about $2 \mathrm{~N}$. However, when the load is increased beyond $2.5 \mathrm{~N}$, its film thickness becomes about the same as those at other frequencies. An explanation could be that with increasing load through adding mass, the natural frequency of the bearing/mass system shifts away from its original value, and so the bearing is no longer being excited at its true natural frequency.

Figure 17 shows the relationship between the minimum air film thickness and load at three different excitation frequencies at and around the natural frequency of $\mathrm{Cu}$ bearing. At the natural frequency of $12.18 \mathrm{kHz}$, the minimum film thickness is also greater in the range of loads experimented.

When the minimum air film thickness for $\mathrm{Al}$ bearing and $\mathrm{Cu}$ bearing are placed side by side, the difference in values is striking, showing that the former is a far better than the latter in terms of load-carrying capacity. The comparison is made in Fig. 18 where the bearing was excited at the natural frequencies of $\mathrm{Al}$ bearing and $\mathrm{Cu}$ bearing.

\section{Discussion}

The CFX simulation modelled the phenomenon for an oscillating squeeze film. To predict the air film thickness, the

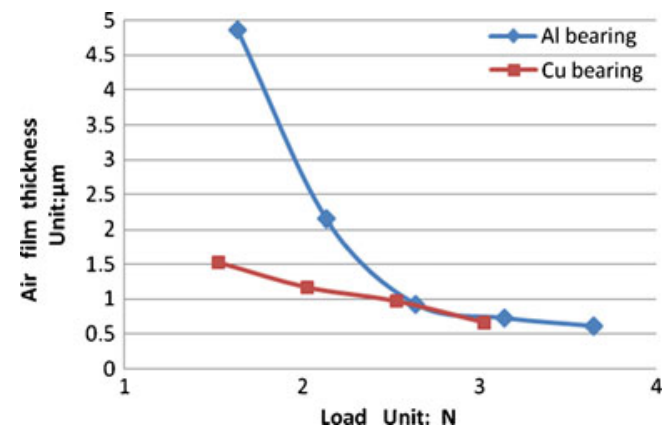

Fig. 18 Comparison between the $\mathrm{Al}$ bearing and the $\mathrm{Cu}$ bearing in load-carrying capacity 
simulation considers not only the pressure end leakage but also the variable excitation frequency, both parameters ignored by the model developed by Wang and Au [7] using the simpler ideal gas law. Therefore, the CFX simulation is expected to give more accurate and realistic results.

In the FEA modelling of the squeeze film bearing, the piezoelectric actuators are accurately represented as a unit that expands and contracts with the driving voltage. In addition, the interaction with the squeeze film bearing as the actuator moves is also accounted for by including the material properties of the two parts. Consequently, the analysis is more accurate.

The modal analysis is used to determine the natural frequencies and mode shapes of both squeeze film bearings. The work proposed in this paper also investigates the bearing response when the excitation frequency coincides with the modal frequency 13. The results of the modal analysis show that $\mathrm{Al}$ bearing has a higher modal frequency than has $\mathrm{Cu}$ bearing in the same mode 13 .

Both $\mathrm{Al}$ and $\mathrm{Cu}$ bearings show a linear relationship between the input DC voltage and the resulting static deformation (Fig. 9). The same result was also obtained by Stolarski and Woolliscroft [2]. But the Al bearing has a bigger static deformation than has the $\mathrm{Cu}$ bearing for the same $\mathrm{DC}$ voltage.

The dynamic deformation is much bigger than the static response. In particular, when driven at mode 13 , the maximum displacement at the fin is roughly $3 \mu \mathrm{m}$ for the $\mathrm{Al}$ bearing (Fig. 11). However, when the excitation frequency shifts from the natural frequency, the amplitude falls (Fig. 11). The small extent of the error indicates a high repeatability in the measurements. The same conclusion can be drawn for the $\mathrm{Cu}$ bearing (Fig. 12). The dynamic deformation of the $\mathrm{Al}$ bearing is greater than that of the $\mathrm{Cu}$ bearing in the same driving condition.

Given the different driving conditions for $\mathrm{AC}$, the bigger film thickness can be obtained when AC is $75 \mathrm{~V}$ (Fig. 15). The bigger film thickness can also be obtained when the excitation frequency coincides with the natural frequency of mode 13 for both $\mathrm{Al}$ and $\mathrm{Cu}$ bearings. However, when the minimum air film thickness for the $\mathrm{Al}$ and $\mathrm{Cu}$ bearings are compared, a significant difference can be observed (Fig. 18). The reasons are: first, the dynamic deformation of the $\mathrm{Al}$ bearing is bigger than that of the $\mathrm{Cu}$ bearing when excited in mode 13 (Fig. 14); second, the modal frequency of the $\mathrm{Al}$ bearing is much higher than that of the $\mathrm{Cu}$ bearing at mode 13, in accordance with Fig 5.

\section{Conclusion}

The findings from this research are summarized as follows:

1. From the CFX model, it is shown that there is a pressure leakage in squeeze film phenomenon when an excitation frequency is below a certain level, $15 \mathrm{kHz}$ presented in the paper (Fig. 2). Also, the CFX model demonstrates that the air film thickness increases, with the oscillation amplitude forming into an exponential fashion in Fig 3. Finally, the positive pressure ratio is presented in the squeeze film action, taking account of pressure end leakage, using the CFX model, as shown in Fig. 4.

2. Mode 13 was identified to have the desirable geometry of the modal shape and applied for both the $\mathrm{Al}$ and $\mathrm{Cu}$ bearings. However, the $\mathrm{Al}$ bearing has a higher modal frequency than has the $\mathrm{Cu}$ bearing in the same mode 13; in the former, the natural frequency is $16.37 \mathrm{kHz}$ and in the latter is $12.32 \mathrm{kHz}$.

3. From the FEA analysis, the linear relationship between the input DC voltage and the radial deformation can be found for both bearings. But, due to the different the material properties, the $\mathrm{Al}$ bearing always has a greater radial deformation than has the $\mathrm{Cu}$ bearing in the three levels of DC voltage: 55, 65 and $75 \mathrm{~V}$.

4. In the dynamic analysis, first, it is found that the dynamic deformation is much greater than the static deformation and, second, the $\mathrm{Al}$ bearing has a greater dynamic response $(2.88 \mu \mathrm{m})$ than the $\mathrm{Cu}$ bearing $(2.41 \mu \mathrm{m})$ when they were both excited at their own excitation frequency of mode 13 and driven in the same condition, $75 \mathrm{~V}$ DC and $75 \mathrm{VAC}$.

5. The load-carrying experiments show that driven at mode 13 for both bearings, $\mathrm{Al}$ one has superior levitation performance than $\mathrm{Cu}$ (Fig. 18). The explanation for the two reasons are that, first, the higher excitation frequency for $\mathrm{Al}$ bearing than $\mathrm{Cu}$ for mode 13, which can reduce the pressure end leakage (Fig. 2), and, second, the oscillation amplitude of the $\mathrm{Al}$ bearing is greater than that of $\mathrm{Cu}$ (Fig. 3). Both of them can be considered influencing the levitation performance; however, it is difficult to judge which one takes a more important part.

Open Access This article is distributed under the terms of the Creative Commons Attribution License which permits any use, distribution, and reproduction in any medium, provided the original author(s) and the source are credited.

\section{References}

1. Stolarski TA, Chai W (2006) Load-carrying capacity generation in squeeze film action. Int J Mech Sci 48(3):736-741

2. Stolarski TA, Woolliscroft SP (2007) Performance of a self-lifting linear air contact. J Mech Eng Sci 221:1103-1115 
3. Yoshimoto S, Anno Y, Sato Y, Hamanaka K (1995) Floating characteristics of squeeze-film gas bearing with elastic hinges for linear motion guide. Int J JSME 60(11):2109-2115

4. Yoshimoto S, Kobayashi H, Miyatake M (2006) Floating characteristics of a squeeze-film bearing for a linear motion guide using ultrasonic vibration. J Tribol Int 40(5):503-511

5. Ono Y, Yoshimoto S, Miyatake M (2009) Impulse-load dynamics of squeeze film gas bearings for a linear motion guide. J Tribol 131 (10): $1-6$

6. Stolarski TA (2009) Numerical modelling and experimental verification of compressible squeeze film pressure. J Tribol Int 43 (6):356-360
7. Wang C, Au YH (2011) Study of design parameters for squeeze film air journal bearing-excitation frequency and amplitude. J Mech Sci 2:147-155

8. Guo ZL, Hirano T, Kirk RG (2005) Application of CFD analysis for rotating machinery - Part 1: Hydrodynamic, hydrostatic bearings and squeeze film damper. J Eng for Gas Turbines Power 127 (10):445-451

9. Wang $\mathrm{C}, \mathrm{Au} \mathrm{YH}$ (2012) Levitation characteristics of a squeezefilm air journal bearing at its normal modes. Int J Adv Manuf Technol 60:1-10

10. Stolarski TA, Chai W (2006) Self-levitation sliding air contact. Int J Mech Sci 48(1):601-620 